\title{
On the optimality of Ramsey taxes in Mirrlees economies*
}

\author{
Borys Grochulski \\ Federal Reserve Bank of Richmond
}

February 15, 2011

\begin{abstract}
In this paper, we show that a simple, linear capital tax - the kind used in the Ramsey analysis - can be optimal in a Mirrlees economy with private information. We extend the Mirrlees approach to optimal taxation by studying taxes side-by-side with another institution, rather than in isolation. We consider an implementation in which agents use unsecured credit and personal bankruptcy to obtain insurance. Taxes are levied to fund government expenditures. An optimal tax system consists of lump-sum taxes and a simple Ramsey tax on wealth. In Mirrlees private information environments, optimal capital taxes do not have to be complicated.
\end{abstract}

JEL Codes: H21, K35

Keywords: optimal taxation, Mirrlees approach, personal bankruptcy, intertemporal wedges

\section{Introduction}

Kocherlakota (2010) summarizes a recent literature often referred to as New Dynamic Public Finance (NDPF). This literature considers a class of economic environments in which agents seek insurance against idiosyncratic, private shocks to their individual productivities. In this class of environments, NDPF derives normative implications for capital income taxation. In this paper, we show that the implications obtained by NDPF depend critically on the assumption that taxes are the only vehicle in the economy through which agents can obtain insurance. Using a simple version of the same environment that NDPF uses to argue that a simple linear capital income tax cannot be optimal, we show that it in fact can when forms of insurance other than taxes are allowed.

In the traditional Ramsey analysis of optimal taxation, it is assumed that capital taxes are proportional and the amount of capital tax due from an agent depends only on the amount of capital held by the agent. (We will call such a tax Ramsey tax.) Traditional analysis does not explain why capital taxes should have this structure.

${ }^{*}$ The views expressed here are those of the author and do not necessarily reflect those of the Federal Reserve Bank of Richmond or the Federal Reserve System. Email: borys.grochulski@rich.frb.org 
NDPF takes a different approach. It obtains not only tax magnitudes but also the structure of the tax system directly from the primitives of the economic environment. ${ }^{1}$ In this approach, a tax system $\mathcal{T}$ is optimal if in a market economy with taxes $\mathcal{T}$ a competitive equilibrium allocation is optimal.

Due to private information, optimal allocations in Mirrlees economies are characterized by the so-called wedges: agents' marginal rates of substitution are not equal to the corresponding marginal rates of transformation. In a market economy in which agents and firms trade capital and labor services in competitive spot markets, prices adjust to equalize the marginal rates of substitution and transformation in equilibrium. Equilibrium allocations, therefore, will not be optimal.

NDPF asks a natural question that arises in this context. With private information, efficiency requires distortions to agents' substitution margins. Proportional taxes can be distortionary. Can proportional taxes therefore be used in a spot capital and labor market economy as corrective distortions that support optimal wedges in equilibrium? In other words, can Ramsey taxes be optimal in Mirrlees private information economies?

NDPF gives a negative answer to this question. NDPF shows in this setting that proportional Ramsey capital taxes allow agents to engage profitably in the so-called joint deviations in which agents shirk and over-save. ${ }^{2}$ The fact that such joint deviations are profitable makes Ramsey taxes insufficient to support optimal allocations as equilibria. Therefore, NDPF concludes, Ramsey capital taxes are not optimal in Mirrlees economies.

In this paper, we show that result holds only under the specific assumption about the implementing mechanism that NDPF uses: taxes are the only vehicle for the provision of insurance in the economy. The only private markets that NDPF considers are spot markets for capital and labor. Under this assumption, it is solely up to the government - its fiscal authority, in particular - to implement optimal state-contingent transfers and to ensure that agents' decision margins are subject to corrective distortions consistent with the optimal wedges.

In addition to spot markets and fiscal transfers, we allow for other markets and institutions in this paper. Using a richer set of markets and institutions, we revisit the question of whether simple Ramsey taxes can be optimal in Mirrlees environments. The answer we obtain is affirmative.

The implementation mechanism we consider includes taxes and personal bankruptcy laws. In addition to spot markets for capital and labor, competitive markets for unsecured credit and bonds function in equilibrium. Taxes are simple: to fund an exogenous level of spending, the government levies lump-sum taxes and a Ramsey tax on capital and bonds. The bankruptcy laws we consider are similar to the optimal bankruptcy rules derived within a dynamic moral hazard model in Grochulski (2010). These rules specify conditions under

\footnotetext{
${ }^{1}$ This approach was first used in Mirrlees (1971). The class of economic environments considered in NDPF is also related to that studied in Mirrlees (1971) in that in both cases agents' individual productivities are private information. In Mirrlees (1971), however, agents are heterogenous ex ante. NDPF typically focuses on ex post heterogeneity evolving over time, i.e., it assumes that agents are ex ante homogenous.

${ }^{2}$ This observation is made in Albanesi and Sleet (2006), Golosov and Tsyvinski (2006), Kocherlakota (2005).
} 
which agents can obtain discharge of unsecured debts. Financial intermediaries issue bonds and take on credit risk, i.e., provide unsecured loans to the agents knowing that a fraction of these loans will be discharged in bankruptcy. In equilibrium, agents face unsecured loan prices and credit limits reflecting this credit risk, and intermediaries make zero profits. Optimal state-contingent transfers - the mutual insurance payments prescribed by the optimal allocation - are implemented via the unsecured credit market and state-contingent bankruptcy discharge, rather than via fiscal transfers.

Prescott and Townsend (1984), Atkeson and Lucas (1992) and Golosov and Tsyvinski (2007) show that competitive markets for exclusive long-term insurance contracts can support an optimal allocation as an equilibrium in private information economies, as long as private information occurs ex post (after contracting) and all trades that agents enter are observable (and contractible). These conditions are met in the Mirrlees economy we study here, as well as in the more general Mirrlees economies studied in NDPF. ${ }^{3}$ The unsecured credit markets and bankruptcy rules we characterize are therefore an implementation alternative to the exclusive long-term contracts of Prescott and Townsend (1984). An attractive feature of our implementation is that, in contrast to the abstract contracts used in the implementation of Prescott and Townsend (1984), Atkeson and Lucas (1992) and Golosov and Tsyvinski (2007), the form of contracts traded, the market structure, and the institutional structure used in our implementation are similar to the unsecured credit markets and the institution of personal bankruptcy that we actually observe in the United States. ${ }^{4}$

In a recent paper, Chetty and Saez (2010) examine how private insurance affects optimal labor income tax formulas obtained in a static Mirrlees environment. They focus on one possible form of private insurance: a within-the-firm insurance scheme in which firms pay workers a fraction of the marginal product of their labor, plus a fixed amount. Similarly, agents pay labor income taxes that are assumed linear, and receive a lump-sum transfer. In our paper, in contrast, labor is paid its marginal product. The non-fiscal insurance mechanism we study is based on unsecured credit markets and personal bankruptcy laws, rather than on within-the-firm insurance. Our model is intertemporal, which allows us to discuss capital taxation. Rather than restricting exogenously the form of taxes to be proportional, we show that such taxes can emerge endogenously as optimal in a Mirrlees environment.

The paper is organized as follows. In Section 2, we lay out a simple version of the Mirrlees environment studied in NDPF. In Section 3, we recall the main results characterizing optimal allocations in this environment. There, as well, we discuss the results of NDPF in some detail and relate our analysis to them. In Section 4, we present out main implementation result in which Ramsey taxes are shown to be optimal in the Mirrlees model. In Section 5, we provide a brief conclusion.

\footnotetext{
${ }^{3}$ As emphasized in Golosov and Tsyvinski (2007), this means that government provision of insurance via taxation amounts to nothing more than crowding out of private insurance in these economies. Since taxes do not provide insurance in the implementation mechanism we study in this paper, there is no crowding out of private insurance in our model.

${ }^{4}$ Grochulski (2010) discusses this similarity in a dynamic model with moral hazard. Extensions of the stochastic structure to more than two points in the support of the skill shock are also discussed there.
} 


\section{Environment}

The environment we consider is very similar to that studied Section 3 of Kocherlakota (2005). There are two dates, $t=0,1$, and a unit measure of ex ante identical agents. At each date $t=0,1$, a single consumption good is produced from capital and labor. Technology of production is described by the production function $F: \mathbb{R}_{+} \times \mathbb{R}_{+} \rightarrow \mathbb{R}_{+}$, where $F(k, y)$ denotes the amount of the consumption good produced from $k$ units of capital and $y$ units of labor. We assume that $F$ is strictly concave, $C^{2}$, exhibits constant returns to scale, and satisfies the usual Inada conditions. For simplicity, we also assume that capital used in production depreciates fully.

The initial aggregate endowment of physical capital $K_{0}$ is distributed uniformly with each out of the unit mass of agents holding $k_{0}=K_{0}$ units of capital. In addition to capital, agents provide effective labor for production, which they generate from skill and labor effort. At $t=0$, all agents have identical skills: one unit of labor effort produces one unit of the effective labor input. Thus, if all agents provide $l_{0}$ units of labor effort, the aggregate supply of effective labor is $Y_{0}=y_{0}=l_{0}$ at this date. The aggregate labor supply $Y_{0}$ and the initial capital $K_{0}$ produce $F\left(K_{0}, Y_{0}\right)$ units of the consumption good at $t=0$. This amount can be consumed or saved as capital $K_{1}$. At $t=1$, agents' skills are subject to a stochastic, individual skill shock $\theta$. Thus, agents become heterogenous at $t=1$. For simplicity, we assume that $\operatorname{Pr}\{\theta \in\{0,1\}\}=1$. Agents whose individual skill realization is $\theta=1$, can, as at $t=0$, convert one unit of labor effort into one unit of effective labor input. Agents whose individual realization of skill is $\theta=0$, however, can convert a unit of effort into zero units of effective labor. ${ }^{5}$ We will denote $\operatorname{Pr}\{\theta\}$ by $\pi_{\theta}>0$ for $\theta \in\{0,1\}$. Each agent's individual realization of $\theta$ is his private information.

In this environment, a (type-identical) allocation $A$ is a list of non-negative numbers

$$
\left\{c_{0},\left(c_{1 \theta}\right)_{\theta \in\{0,1\}}, l_{0},\left(l_{1 \theta}\right)_{\theta \in\{0,1\}}, Y_{0}, Y_{1}, K_{1}\right\},
$$

where $c_{0}$ is per capita consumption $t=0$, and $c_{1 \theta}$ is per capita consumption of agents with skill $\theta$ at $t=1$. The expected ex ante utility a representative agent obtains under allocation $A$ is given by

$$
u\left(c_{0}\right)-v\left(l_{0}\right)+\beta \sum_{\theta \in\{0,1\}} \pi_{\theta}\left\{u\left(c_{1 \theta}\right)-v\left(l_{1 \theta}\right)\right\}
$$

where $u$ and $v$ are strictly increasing, $C^{2}$ functions with $u^{\prime \prime}<0, v^{\prime \prime}>0$, and $v(0)=0$.

\footnotetext{
${ }^{5}$ Our analysis can be generalized to the case of positive productivity in both states without changing our main result concerning the optimality of simple Ramseyan capital taxes.
} 
An allocation is resource-feasible if it satisfies the following resource constraints

$$
\begin{aligned}
c+K_{1}+G_{0} & \leq F\left(K_{0}, Y_{0}\right), \\
Y_{0} & =l_{0} \\
\sum_{\theta \in\{0,1\}} \pi_{\theta} c_{1 \theta}+G_{1} & \leq F\left(K_{1}, Y_{1}\right), \\
Y_{1} & =\sum_{\theta \in\{0,1\}} \pi_{\theta} \theta l_{1 \theta},
\end{aligned}
$$

where $G_{t}$ is a fixed level of government spending in period $t=0,1$. It is without loss of generality to only consider allocations with $l_{10}=0$. This is because the agents whose skill at $t=1$ is $\theta=0$ cannot provide any effective labor into production. It would therefore be a waste to have them exert a positive amount of labor effort.

Because skills at $t=1$ are private information, we restrict attention to allocations that satisfy the following incentive compatibility (IC) constraint

$$
u\left(c_{11}\right)-v\left(l_{11}\right) \geq u\left(c_{10}\right) .
$$

This constraint requires that the skilled agents at $t=1$ do not prefer to mimic the unskilled ones by providing zero effective labor and consuming the amount that allocation $A$ assigns to unskilled agents, $c_{10}$. By the Revelation Principle, restricting attention to IC allocations is without loss of generality.

\section{Optimal allocations, wedges, and taxes}

Allocation $A$ is optimal if it is resource-feasible, IC, and if among all resource-feasible and IC allocations it maximizes the ex ante welfare of the representative agent. Thus, $A$ is optimal if and only if it solves the following social planning problem: maximize (1) subject to the resource constraints (2)-(5) and the IC constraint (6).

Denote an optimal allocation by

$$
A^{*}=\left\{c_{0}^{*},\left(c_{1 \theta}^{*}\right)_{\theta \in\{0,1\}}, l_{0}^{*},\left(l_{1 \theta}^{*}\right)_{\theta \in\{0,1\}}, Y_{0}^{*}, Y_{1}^{*}, K_{1}^{*}\right\}
$$

As noted above, since effort of an agent whose $\theta=0$ is unproductive, $l_{10}^{*}=0$. It is straightforward to use the first-order conditions of the social planning problem to demonstrate the following properties of $A^{*}$ (see Kocherlakota 2005, Section 3): the IC constraint (6) is binding at $A^{*}$,

$$
\begin{aligned}
l_{0}^{*}>0, l_{11}^{*}>0, & c_{11}^{*}>c_{10}^{*}>0, \\
u^{\prime}\left(c_{0}^{*}\right) & =\frac{v^{\prime}\left(l_{0}^{*}\right)}{w_{0}^{*}}, \\
u^{\prime}\left(c_{11}^{*}\right) & =\frac{v^{\prime}\left(l_{11}^{*}\right)}{w_{1}^{*}},
\end{aligned}
$$


and

$$
\frac{1}{u^{\prime}\left(c_{0}^{*}\right)}=\frac{1}{r_{1}^{*} \beta} \mathbb{E}\left[\frac{1}{u^{\prime}\left(c_{1}^{*}\right)}\right]
$$

where

$$
r_{t}^{*}=F_{1}\left(K_{t}^{*}, Y_{t}^{*}\right), w_{t}^{*}=F_{2}\left(K_{t}^{*}, Y_{t}^{*}\right) \text { for } t=0,1 .
$$

Equations (7) and (8) tell us that, if labor services are paid their marginal product, the productive agents' disutility of making one extra dollar of labor income at $A^{*}$ is equal to the utility of consuming it. This means that there are no intratemporal distortions (wedges) at $A^{*}$ : if agents are given the allocation $A^{*}$ and can earn in period $t=0,1$ wages $w_{t}^{*}=F_{2}\left(K_{t}^{*}, Y_{t}^{*}\right)$, they would not want to deviate from the optimal allocation by working a different amount than what the optimal allocation prescribes.

Equation (9) is the so-called Inverse Euler Equation. ${ }^{6}$ Bringing the expectation inside the inverse function, using Jensen inequality and the fact that $c_{11}^{*} \neq c_{10}^{*}$, we get that the optimal allocation $A^{*}$ satisfies

$$
u^{\prime}\left(c_{0}^{*}\right)<r_{1}^{*} \beta \mathbb{E}\left[u^{\prime}\left(c_{1}^{*}\right)\right] .
$$

This inequality tells us that there is a distortion in the inter-temporal margin at $A^{*}$, which often is referred to as the intertemporal wedge: if capital services are paid their marginal product, $r_{t}^{*}=F_{1}\left(K_{t}^{*}, Y_{t}^{*}\right)$, the disutility of reducing consumption $c_{0}$ somewhat and investing a bit more in capital $K_{1}$ is smaller than the resulting expected benefit of having more capital at $t=1$. Thus, if agents are given allocation $A^{*}$ and can save (accumulate capital) without any distortions, they would like to trade away from the optimum $A^{*}$ by saving more than what is socially optimal. In this sense, agents are savings-constrained at $A^{*}$. Inequality (10) is important because it makes clear that if $A^{*}$ is to be consistent with agents' individual utility maximization, a necessary condition for equilibrium, the intertemporal margin cannot be undistorterd.

In addition, we will use the following two properties of the optimum $A^{*}$ :

$$
r_{1}^{*} \beta u^{\prime}\left(c_{11}^{*}\right)<u^{\prime}\left(c_{0}^{*}\right)<r_{1}^{*} \beta u^{\prime}\left(c_{10}^{*}\right)
$$

and

$$
w_{1}^{*} l_{11}^{*}-c_{11}^{*}>w_{1}^{*} l_{10}^{*}-c_{10}^{*} .
$$

The inequalities in (11) tell us that agents are insurance-constrained at $A^{*}$. If agents could insure (or hedge) their individual shocks $\theta$ at a fair-odds premium, they would like to trade away from $A^{*}$ by purchasing additional insurance. Inequality (12) shows that the optimal allocation $A^{*}$ delivers a state-contingent transfer from the productive agents to the unproductive ones at $t=1 .^{7}$

\footnotetext{
${ }^{6}$ Rogerson (1985) derives this equation in a moral hazard model. Golosov, Kocherlakota and Tsyvinski (2003) derive this equation in a general dynamic Mirrlees economy with privately evolving skills.

${ }^{7}$ Proof of (11) follows simply from the first-order conditions of the social planning problem. Proof of
} 


\subsection{Connecting wedges and taxes}

NDPF starts out with a natural connection between the intertemporal wedge and a tax on savings, and points out a problem with it. The natural connection is as follows. The agents' incentive to over-save, relative to $A^{*}$, can be removed if a proportional tax is imposed on capital income in period 1 with the tax rate $\tau$ equal

$$
\tau^{*}=1-\frac{u^{\prime}\left(c_{0}^{*}\right)}{r_{1}^{*} \beta \mathbb{E}\left[u^{\prime}\left(c_{1}^{*}\right)\right]}
$$

The fact that $\tau^{*}$ is strictly positive could provide an efficiency-based role for positive capital taxes. Such an efficiency-based argument is something that the optimal taxation literature started by Ramsey (1927) has been lacking.

The problem with this connection that NDPF points out is as follows. There is one more wedge at the optimum $A^{*}$ :

$$
u^{\prime}\left(c_{0}^{*}\right)<r_{1}^{*} \beta u^{\prime}\left(c_{10}^{*}\right)
$$

We can call this wedge a shirker's intertemporal wedge. If an agent shirks, i.e., decides at $t=0$ that he will exert at $t=1$ effort equal zero in both states $\theta$ (that means he will supply zero units of effective labor even when his skill shock realization is $\theta=1$ ), then the intertemporal trade-off relevant to him is the one between the marginal utility $u^{\prime}\left(c_{0}^{*}\right)$ and the marginal utility $u^{\prime}\left(c_{10}^{*}\right)$, not $\mathbb{E}\left[u^{\prime}\left(c_{1}^{*}\right)\right]$. Since $\theta$ is not publicly observable, the allocation $A^{*}$ assigns consumption in period 1 on the basis of the observed effective labor input $y_{1}=\theta l_{1}$. A shirking agent will be assigned at $t=1$ consumption $c_{10}^{*}$ with probability one because he always produces $y_{1}=0$. Since $u^{\prime}\left(c_{10}^{*}\right)>\mathbb{E}\left[u^{\prime}\left(c_{1}^{*}\right)\right]$, the tax rate $\tau^{*}$ in (13), although high enough to deter over-saving by an agent who does not shirk, is not high enough to deter a shirker from over-saving. Thus, a shirker prefers to over-save and shirk over simply shirking. Because the IC constraint (6) is binding at $A^{*}$, shirking without over-saving gives an agent as much utility as non-shirking. Thus, a "joint deviation" plan of both shirking and over-saving gives the agent more utility than non-shirking gives him. Therefore, under the simple Ramsey tax $\tau^{*}$ agents would choose to over-save and shirk. Thus, $\tau^{*}$ is not sufficient to implement $A^{*}$.

From this NDPF concludes that the simple Ramsey capital tax $\tau^{*}$ cannot be optimal

inequality (12) is as follows. Let (an indifference curve) $c(l)$ be defined implicitly by

$$
u(c(l))-v(l)=u\left(c_{11}^{*}\right)-v\left(l_{11}^{*}\right)
$$

for $l \geq 0$. Because $u^{\prime},-v^{\prime}>0, c(\cdot)$ is a strictly increasing function. Because $u^{\prime \prime}, v^{\prime \prime}>0, c(\cdot)$ is strictly convex. Because the IC constraint binds at the optimum and $l_{10}^{*}=0$, we have $c_{10}^{*}=c(0)$ and $c_{11}^{*}=c\left(l_{11}^{*}\right)$. Since $l_{11}^{*}>l_{10}^{*}=0$, the strict convexity of $c(\cdot)$ implies that the slope of the line connecting in the plane $(l, c)$ points $\left(0, c_{10}^{*}\right)$ and $\left(l_{11}^{*}, c_{11}^{*}\right)$ is strictly smaller than the slope of $c(\cdot)$ at $l_{11}^{*}$. Thus

$$
\frac{c_{11}^{*}-c_{10}^{*}}{l_{11}^{*}-0}<\frac{v^{\prime}\left(l_{11}^{*}\right)}{u^{\prime}\left(c_{11}^{*}\right)}=w_{1}^{*}
$$

where the equality follows from (8). 
in this model with private skill shocks. If $\tau^{*}$ is not optimal, clearly, no Ramsey capital tax can be optimal in this model because $\tau^{*}$ provides exactly the amount of distortion needed to support the intertemporal wedge of a non-shirker. ${ }^{8}$

In the next section, we show how this conclusion is overturned when a richer implementation mechanism is allowed. The negative result obtained in NDPF depends critically on the assumption that spot markets for labor and capital are the only markets that function in the economy. The market mechanism studied in the next section includes a richer set of markets allowing agents to obtain insurance via a non-fiscal means.

\section{Implementation with unsecured credit, bankruptcy, and taxes}

In this section, we study an implementation mechanism in which agents use unsecured credit and bankruptcy to obtain insurance against their productivity shocks, while taxes are used to fund government spending.

In this implementation, unsecured credit markets work as in Grochulski (2010). Competitive intermediaries trade with the agents using two assets: unsecured, defaultable loans $h$, and riskless bonds $b$. Each agent faces a limit $\bar{h}$ on the amount of unsecured loans that he can take out with the intermediaries (it is his total credit limit with the whole industry). ${ }^{9}$ The intermediaries hold risky loans as assets, and the bonds issued are their liabilities. Bonds $b$ sell at $t=0$ at the discount price $q$. The gross interest rate charged on the defaultable loans is $R$. Intermediaries diversify away the individual-specific risks by holding large (positive-measure) portfolios of defaultable loans. Intermediaries face a competitive market for unsecured loans. They decide whether to enter on not. If they do, they put in a credit offer on competitive terms. On these terms, the intermediaries expect loan demand volume $h^{e}$, a fraction $D^{e}$ of the loans going into default at $t=1$, and an expected principal recovery rate given default $\gamma^{e}$. In equilibrium, these expectations will be fulfilled.

The bankruptcy code works as follows. There is an eligibility criterion $f$ and an asset exception level $\bar{e}$. The eligibility condition simply says that only agents with zero labor income can be granted debt discharge in bankruptcy. If an agent files for bankruptcy in period 1 , he gives up his assets in excess of the exemption level $\bar{e}$. In particular, the bankruptcy law says that discharge can be granted only to agents who have zero labor

\footnotetext{
${ }^{8} \mathrm{NDPF}$ proceeds by deriving more complex - non-Ramsey - tax systems that make the joint deviation plan unprofitable to would-be shirkers. Kocherlakota (2005) and Albanesi and Sleet (2006) show that one way in which this can be done is to make the marginal tax rate on capital state-contingent. Golosov and Tsyviski (2006) design an optimal disability insurance system in a model in which disablity is private information. They show that asset-testing for transfers to the disabled agents can eliminte the joint deviation problem as well.

${ }^{9}$ Grochulski (2010) discusses how the industry-wide credit limit $\bar{h}$ can be obtained as an outcome of strategic interaction between financial intermediaries competing with one another. Thus, the credit limit is not an exogenous object but rather an endogenous consequence of intermediaries' competition with rational expectations and fully observable trades subject to exogenous rules regulating loan discharge in personal bankruptcy.
} 
income at $t=1$ and who surrender their assets. Assets up to the value $\bar{e}$ are exempt, i.e., are returned to the agent. Assets in excess of $\bar{e}$ are non-exempt, i.e., are distributed to the lenders whose unsecured loans are being discharged. At $t=1$, agents assets are $r_{1} k_{1}+b$.

Intermediaries take as given prices $i, R$, and the credit limit $\bar{h}$. They form correct expectations of $h^{e}, D^{e}, \gamma^{e}$. Since they have zero external equity at $t=0$, in order to balance asset and liabilities at $t=0$, the intermediaries must satisfy at $t=0$ the budget constraint $h^{e}=q b$. The expected profits are

$$
\begin{aligned}
\Pi_{1} & =\left(1-D^{e}\right) R h^{e}+D^{e} \gamma h^{e}-b \\
& =\left(\left(1-D^{e}\right) R+D^{e} \gamma^{e}-q^{-1}\right) h^{e}
\end{aligned}
$$

where the second line uses the budget constraint. Free entry into intermediation gives us immediately that $\left(1-D^{e}\right) R+D^{e} \gamma^{e}-q^{-1}=0$ if $h^{e}>0$. The number of intermediaries operating in this competitive environment is indeterminate. It can be normalized to one.

Taxes are as follows. There is a proportional Ramsey wealth tax $\tau$ at date 1 , and lump-sum taxes $T_{t}$ at $t=0,1$.

Because we are only considering type-identical allocations in this paper and the initial endowment of aggregate capital $K_{0}$ is distributed evenly among all agents, we can speak of the representative agent as of $t=0$. The initial capital holdings of the representative agent are $k_{0}=K_{0}$. With the asset markets, bankruptcy, and taxes described above, the representative agent's problem is to choose nonnegative consumption $c_{0}, c_{1 \theta}$, labor $l_{0}, l_{1 \theta}$, asset positions $h, b, k_{1}$, and a discrete bankruptcy filing plan $\left(d_{0}, d_{1}\right) \in\{0,1\} \times\{0,1\}$ so as to maximize (1) subject to

$$
\begin{aligned}
h \leq & \bar{h} \\
c_{0}+q b+k_{1} \leq & w_{0} l_{0}+r_{0} k_{0}+h-T_{0}, \\
d_{\theta} \leq & f\left(w_{1} \theta l_{1 \theta}\right) \\
c_{1 \theta} \leq & w_{1} \theta l_{1 \theta}+r_{1} k_{1}+b-\left(1-d_{\theta}\right) R h \\
& -d_{\theta} \max \left\{r_{1} k_{1}+b-\bar{e}, 0\right\}-\tau\left(r_{1} k_{1}+b\right)-T_{1},
\end{aligned}
$$

where the bankruptcy eligibility condition $f$ is given by the indicator function of the number zero, and the asset exemption level $\bar{e}$ is a positive number.

Definition 1 Given a set of taxes $\left(\tau, T_{0}, T_{1}\right)$ and bankruptcy laws $(f, \bar{e})$, competitive equilibrium with taxes and bankruptcy consists of an allocation

$$
\hat{A}=\left\{\hat{c}_{0},\left(\hat{c}_{1 \theta}\right)_{\theta \in\{0,1\}}, \hat{l}_{0},\left(\hat{l}_{1 \theta}\right)_{\theta \in\{0,1\}}, \hat{Y}_{0}, \hat{Y}_{1}, \hat{K}_{1}\right\}
$$

the agent's loan and asset positions $\hat{h}, \hat{b}, \hat{k}_{1}$ and bankruptcy filing choices $\left(\hat{d}_{\theta}\right)_{\theta \in\{0,1\}}$, prices $q, R,\left\{r_{t}, w_{t}\right\}_{t=0,1}$, expectations $D^{e}, \gamma^{e}$, he and a credit limit $\bar{h}$ such that: (a) the values $\hat{c}_{0}$, 
$\left(\hat{c}_{1 \theta}\right)_{\theta \in\{0,1\}}, \hat{l}_{0},\left(\hat{l}_{1 \theta}\right)_{\theta \in\{0,1\}}, \hat{h}, \hat{b}, \hat{k}_{1}$ and $\left(\hat{d}_{\theta}\right)_{\theta \in\{0,1\}}$ solve the agent's utility maximization problem, (b) intermediaries break even: $\Pi_{1}=0$, (c) capital and labor are paid their respective marginal products

$$
r_{t}=F_{1}\left(\hat{K}_{t}, \hat{Y}_{t}\right), w_{t}=F_{2}\left(\hat{K}_{t}, \hat{Y}_{t}\right) \text { for } t=0,1,
$$

(d) consumption, labor, and capital markets clear

$$
\begin{aligned}
\hat{c}_{0}+\hat{K}_{1}+G_{0} & =F\left(\hat{K}_{0}, \hat{Y}_{0}\right), \\
\hat{K}_{1} & =\hat{k}_{1}, \\
\hat{Y}_{0} & =\hat{l}_{0}, \\
\sum_{\theta \in\{0,1\}} \pi_{\theta} \hat{c}_{1 \theta}+\hat{G}_{1} & =F\left(\hat{K}_{1}, \hat{Y}_{1}\right), \\
\hat{Y}_{1} & =\sum_{\theta \in\{0,1\}} \pi_{\theta} \theta \hat{l}_{1 \theta},
\end{aligned}
$$

and (e) expectations are correct

$$
\begin{aligned}
h^{e} & =\hat{h}, \\
D^{e} & =\sum_{\theta \in\{0,1\}} \pi_{\theta} \hat{d}_{\theta}, \\
\gamma^{e} & =\frac{\max \left\{r_{1} \hat{k}_{1}+\hat{b}-\bar{e}, 0\right\}}{\hat{h}} \text { if } \hat{h}>0 .
\end{aligned}
$$

Note that this definition implies that in equilibrium the government balances its budget every period.

The next definition specifies what implementation means in this context.

Definition 2 Taxes $\left(\tau, T_{0}, T_{1}\right)$ and bankruptcy laws $(f, \bar{e})$ implement an optimum $A^{*}$ if there exists a competitive equilibrium with taxes and bankruptcy such that the equilibrium allocation $\hat{A}$ coincides with the optimal allocation $A^{*}$.

We are now ready to show an implementation result with Ramsey taxes.

Theorem 1 Let $A^{*}$ be optimal. Let taxes be $\left(\tau^{*}, T_{0}^{*}, T_{1}^{*}\right)$, where $\tau^{*}$ is given in (13) and

$$
\begin{aligned}
& T_{0}^{*}=G_{0}, \\
& T_{1}^{*}=G_{1}-\tau^{*}\left(r_{1}^{*} K_{1}^{*}+\pi_{1}^{*}\left(y_{11}^{*}-c_{11}^{*}+c_{10}^{*}\right)\right) .
\end{aligned}
$$

Let the bankruptcy code $(f, \bar{e})$ be given by

$$
\begin{aligned}
f\left(y_{1}\right) & =\chi_{\{0\}}\left(y_{1}\right), \\
\bar{e} & =r_{1}^{*} K_{1}^{*}+\pi_{1}^{*}\left(w_{1}^{*} l_{11}^{*}-c_{11}^{*}+c_{10}^{*}\right),
\end{aligned}
$$

where $\chi$ is the indicator function. These taxes and bankruptcy rules implement $A^{*}$. 


\subsection{Proof of Theorem 1}

The proof is constructive. We first specify a list of objects (prices, credit limits, expectations, agent's loan and asset choices) that, we claim, along with the allocation $\hat{A}=A^{*}$, are an equilibrium. Then we check that this candidate equilibrium in fact does satisfy the equilibrium conditions (a)-(e) of Definition 1.

We specify candidate equilibrium prices as

$$
\begin{aligned}
r_{t} & =r_{t}^{*}, w_{t}=w_{t}^{*} \text { for } t=0,1, \\
q & =1 / r_{1}^{*} \\
R & =r_{1}^{*} / \pi_{1},
\end{aligned}
$$

and the unsecured credit limit as

$$
\bar{h}=\pi_{1}\left(w_{1}^{*} l_{11}^{*}-c_{11}^{*}+c_{10}^{*}\right) / r_{1}^{*}
$$

We take the intermediaries' expectations to be

$$
h^{e}=\bar{h}, D^{e}=\pi_{0}, \gamma^{e}=0,
$$

the agent's loan and asset holding choices to be

$$
\hat{h}=\bar{h}, \hat{b}=\bar{h} r_{1}^{*}, \hat{k}_{1}=K_{1}^{*}
$$

and the bankruptcy filing plan to be

$$
d_{0}=1, d_{1}=0
$$

Now we proceed to checking that these quantities in fact satisfy the equilibrium conditions of Definition 1. Because the consistency and market clearing conditions (b)-(e) are expressed simply as algebraic equalities, direct substitution of the proposed equilibrium values into these equalities confirms that conditions (b)-(e) are satisfied. Condition (a), however, is a maximization condition. The reminder of the proof is devoted to showing that (1) the proposed equilibrium choices belong to the representative agent's budget set, and (2) the agent cannot benefit by deviating from the proposed equilibrium behavior.

First we check that the consumption, unsecured loan, assets, and bankruptcy choices are in the budget set. Substituting the proposed equilibrium values and the tax $T_{0}^{*}$ from (14) into the budget constraint at date 0 , we get

$$
c_{0}^{*}+\bar{h} r_{1}^{*} / r_{1}+K_{1}^{*}=w_{0}^{*} l_{0}^{*}+r_{0}^{*} K_{0}+\bar{h}-G_{0} .
$$

Using (16), we see that equation holds true because $w_{0}^{*} l_{0}^{*}+r_{0}^{*} K_{0}=F\left(K_{0}, Y_{0}^{*}\right)$ and $A^{*}$ satisfies (2). Substituting taxes (13) and (15) and the proposed equilibrium choices into the 
date-1 budget constraints we have

$c_{10}^{*}=w_{1}^{*} 0+r_{1}^{*} K_{1}^{*}+\bar{h} r_{1}^{*}-0 \bar{h} r_{1}^{*} / \pi_{1}-1 \max \left\{r_{1}^{*} K_{1}^{*}+\bar{h} r_{1}^{*}-\bar{e}, 0\right\}-\tau^{*}\left(r_{1}^{*} K_{1}^{*}+\bar{h} r_{1}^{*}\right)-T_{1}^{*}$,

$c_{11}^{*}=w_{1}^{*} l_{11}^{*}+r_{1}^{*} K_{1}^{*}+\bar{h} r_{1}^{*}-\bar{h} r_{1}^{*} / \pi_{1}-0 \max \left\{r_{1}^{*} K_{1}^{*}+\bar{h} r_{1}^{*}-\bar{e}, 0\right\}-\tau^{*}\left(r_{1}^{*} K_{1}^{*}+\bar{h} r_{1}^{*}\right)-T_{1}^{*}$.

Using $T_{1}^{*}=G_{1}-\tau^{*}\left(r_{1}^{*} K_{1}^{*}+r_{1}^{*} \bar{h}\right)$ and $\bar{e}=r_{1}^{*} K_{1}^{*}+r_{1}^{*} \bar{h}$, we can simplify these to

$$
\begin{aligned}
& c_{10}^{*}=r_{1}^{*} K_{1}^{*}+\bar{h} r_{1}^{*}-G_{1}, \\
& c_{11}^{*}=w_{1}^{*} l_{11}^{*}+r_{1}^{*} K_{1}^{*}+\bar{h} r_{1}^{*}\left(1-1 / \pi_{1}\right)-G_{1} .
\end{aligned}
$$

Since $F\left(K_{1}^{*}, Y_{1}^{*}\right)=w_{1}^{*}\left(\pi_{1} l_{11}^{*}+\pi_{0} 0\right)+r_{1}^{*} K_{1}^{*}$, resource-feasibility of $A^{*}$ implies that $G_{1}=$ $w_{1}^{*} \pi_{1} l_{11}^{*}+r_{1}^{*} K_{1}^{*}-\pi_{0} c_{10}^{*}-\pi_{1} c_{11}^{*}$. Substituting this into the above two equations and simplifying terms, we get

$$
\begin{aligned}
& c_{10}^{*}=\bar{h} r_{1}^{*}-w_{1}^{*} \pi_{1} l_{11}^{*}+\pi_{0} c_{10}^{*}+\pi_{1} c_{11}^{*}, \\
& c_{11}^{*}=\pi_{0} w_{1}^{*} l_{11}^{*}+\bar{h} r_{1}^{*} \pi_{0} / \pi_{1}+\pi_{0} c_{10}^{*}+\pi_{1} c_{11}^{*} .
\end{aligned}
$$

Using (16) we check that the right hand side of (18) is indeed $c_{10}^{*}$ and the right hand side of (19) is indeed $c_{11}^{*}$.

We also need to show that $\hat{b}$ and $\hat{h}$ are nonnegative. They both are non-negative if and only if $w_{1}^{*} l_{11}^{*}-c_{11}^{*}+c_{10}^{*} \geq 0$. Inequality (12) shows that this inequality holds strictly, so $\hat{b}$ and $\hat{h}$ are in fact strictly positive. This confirms budget-feasibility. Next, we need to show that the agent could not do better by deviating from the proposed choices.

The agent needs to make a discrete choice of a bankruptcy plan. There are four possible bankruptcy plans the agent can choose among: $\left(d_{0}, d_{1}\right) \in\{(1,0),(1,1),(0,0),(0,1)\}$. The proposed equilibrium plan is $\left(d_{0}, d_{1}\right)=(1,0)$. We will go through all four cases to show that the proposed equilibrium plan is the best for the agent. Also, we will show that conditional on $\left(d_{0}, d_{1}\right)=(1,0)$, the rest of the proposed equilibrium behavior maximizes the utility of the representative agent.

Case I. $\left(d_{0}, d_{1}\right)=(1,0)$, i.e., the agent uses bankruptcy when $\theta=0$ and does not when $\theta=1$.

Conditional on this bankruptcy plan, the agent's budget constraints are as follows

$$
\begin{aligned}
h & \leq \bar{h} \\
c_{0}+q b+k_{1} & \leq w_{0} l_{0}+r_{0} k_{0}+h-T_{0}^{*}, \\
c_{10} & \leq w_{1} 0+r_{1} k_{1}+b-\max \left\{r_{1} k_{1}+b-\bar{e}, 0\right\}-\tau^{*}\left(r_{1} k_{1}+b\right)-T_{1}^{*} \\
c_{11} & \leq w_{1} l_{11}+r_{1} k_{1}+b-R h-\tau^{*}\left(r_{1} k_{1}+b\right)-T_{1}^{*} .
\end{aligned}
$$

We will relax this problem by dropping the non-positive term $-\max \left\{r_{1} k_{1}+b-\bar{e}, 0\right\}$ from the right-hand side of (20). That is, we replace (20) with

$$
c_{10} \leq w_{1} 0+r_{1} k_{1}+b-\tau^{*}\left(r_{1} k_{1}+b\right)-T_{1}^{*} .
$$


We now show that the proposed equilibrium behavior solves the relaxed problem. Then, we will check that this solution is also feasible in the unrelaxed problem.

The relaxed problem is a concave maximization problem. The first-order (FO) conditions along with the budget constraints at equality are necessary and sufficient. The FO conditions are as follows:

$$
\begin{aligned}
v^{\prime}\left(l_{0}\right) & =u^{\prime}\left(c_{0}\right) w_{0}, \\
v^{\prime}\left(l_{11}\right) & =u^{\prime}\left(c_{11}\right) w_{1}, \\
u^{\prime}\left(c_{0}\right) & \geq R \beta \pi_{1} u^{\prime}\left(c_{11}\right) \text { with equality if } h<\bar{h}, \\
u^{\prime}\left(c_{0}\right) & =q^{-1} \beta\left(1-\tau^{*}\right) \mathbb{E}\left[u^{\prime}\left(c_{1}\right)\right], \\
u^{\prime}\left(c_{0}\right) & =r_{1} \beta\left(1-\tau^{*}\right) \mathbb{E}\left[u^{\prime}\left(c_{1}\right)\right] .
\end{aligned}
$$

Simple substitution of the proposed equilibrium values for $c, l$, and $h$ verifies that these values solve this problem. In particular, the intra-temporal conditions for labor follow from (7) and (8). The intertemporal condition with respect to $h$ follows from the left inequality in (11). Using $q^{-1}=r_{1}=r_{1}^{*}$ and the expression for $\tau^{*}$ in (13), we get that the intertemporal conditions with respect to $b$ and $k_{1}$ are satisfied as well. (We note that only the condition with respect to $h$ is binding here.)

We now note that the solution to the relaxed problem is also feasible in the unrelaxed problem because $-\max \left\{r_{1}^{*} K_{1}+\hat{b}-\bar{e}, 0\right\}=0$. This verifies that the proposed equilibrium behavior solves the agent's problem conditional on $\left(d_{0}, d_{1}\right)=(1,0)$. The utility the agent obtains in this case is thus

$$
u\left(c_{0}^{*}\right)-v\left(l_{0}^{*}\right)+\beta \pi_{1}\left\{u\left(c_{11}^{*}\right)-v\left(l_{11}^{*}\right)\right\}+\beta \pi_{0} u\left(c_{10}^{*}\right) .
$$

Case II. $\left(d_{0}, d_{1}\right)=(1,1)$, i.e., the agent goes bankrupt in both individual states $\theta$.

In order to be eligible to go bankrupt in state $\theta=1$, the agent must choose $l_{11}=0$. This means that $l_{11}=l_{10}$, i.e., the agent behaves identically in both states $\theta=0,1$. The agent thus chooses $c_{0}, l_{0}, h, b, k_{1}$ and $c_{1}$ so as to maximize

$$
u\left(c_{0}\right)-v\left(l_{0}\right)+\beta\left[u\left(c_{1}\right)-v(0)\right]
$$

subject to

$$
\begin{aligned}
h & \leq \bar{h} \\
c_{0}+q b+k_{1} & \leq w_{0} l_{0}+r_{0} k_{0}+h-T_{0}^{*} \\
c_{1} & \leq r_{1} k_{1}+b-\max \left\{r_{1} k_{1}+b-\bar{e}, 0\right\}-\tau^{*}\left(r_{1} k_{1}+b\right)-T_{1}^{*} .
\end{aligned}
$$

We will show that $c_{0}=c_{0}^{*}, l_{0}=l_{0}^{*}, h=\hat{h}, b=\hat{b}, k_{1}=K_{1}^{*}$ and $c_{1}=c_{10}^{*}$ solve this problem. Since under the bankruptcy filing plan considered in this case the unsecured loan is repaid in neither state $\theta$, the agent, clearly, chooses $h=\bar{h}$. We can thus rewrite the budget 
constraints as

$$
\begin{aligned}
c_{0}+q b+k_{1} & \leq w_{0} l_{0}+r_{0} k_{0}+\bar{h}-T_{0}^{*}, \\
c_{1} & \leq \min \left\{r_{1} k_{1}+b, \bar{e}\right\}-\tau^{*}\left(r_{1} k_{1}+b\right)-T_{1}^{*} .
\end{aligned}
$$

If the agent's total savings in bonds and physical capital equal or exceed $\bar{e}$ at $t=1$, the marginal return on the savings is zero. The price of savings at $t=0$ is strictly positive. Thus, it will never be optimal for the agent to choose $r_{1} k_{1}+b$ larger than $\bar{e}$. We can therefore rewrite the above budget constraints as

$$
\begin{aligned}
c_{0}+q b+k_{1} & \leq w_{0} l_{0}+r_{0} k_{0}+\bar{h}-T_{0}^{*}, \\
c_{1} & \leq\left(1-\tau^{*}\right)\left(r_{1} k_{1}+b\right)-T_{1}^{*}, \\
r_{1} k_{1}+b & \leq \bar{e} .
\end{aligned}
$$

The problem of maximization of (21) subject to these budget constraints is a convex problem. The set of first-order necessary and sufficient conditions for the maximum consists of the budget equations and

$$
\begin{aligned}
v^{\prime}\left(l_{0}\right) & =w_{0} u^{\prime}\left(c_{0}\right) \\
u^{\prime}\left(c_{0}\right) & \leq\left(1-\tau^{*}\right) q^{-1} \beta u^{\prime}\left(c_{1}\right) \text { with equality if } r_{1} k_{1}+b<\bar{e} \\
u^{\prime}\left(c_{0}\right) & \leq\left(1-\tau^{*}\right) r_{1} \beta u^{\prime}\left(c_{1}\right) \text { with equality if } r_{1} k_{1}+b<\bar{e}
\end{aligned}
$$

That values $c_{0}^{*}$ and $l_{0}^{*}$ satisfy the first of these conditions follows from (7). Using (13), substituting $c_{0}=c_{0}^{*}, c_{1}=c_{10}^{*}, q^{-1}=r_{1}=r_{1}^{*}$, and cancelling out terms, the second and third conditions reduce to a single condition

$$
1 \leq \frac{u^{\prime}\left(c_{10}^{*}\right)}{\mathbb{E}\left[u^{\prime}\left(c_{1}^{*}\right)\right]} \text { with equality if } r_{1} k_{1}+b<\bar{e}
$$

which is satisfied because $\mathbb{E}\left[u^{\prime}\left(c_{1}^{*}\right)\right]<u^{\prime}\left(c_{10}^{*}\right)$ and $r_{1}^{*} K_{1}+\hat{b}=\bar{e}$. Thus, the values we proposed as a solution to this problem in fact solve it. (Note that the constraint $r_{1} k_{1}+b \leq \bar{e}$ binds in this problem.) In sum, the value that the agent can obtain using the bankruptcy strategy $d_{0}=d_{1}=1$ equals

$$
u\left(c_{0}^{*}\right)-v\left(l_{0}^{*}\right)+\beta u\left(c_{1}^{*}\right) .
$$

Because the IC constraint holds at the optimum $A^{*}$ with equality, this amount of utility is exactly equal to that the agent obtains in Case I. Thus, the proposed equilibrium behavior is weakly better for the agent than the strategy of going bankrupt is both states.

Case III. $\left(d_{0}, d_{1}\right)=(0,0)$, i.e., the agent never uses the bankruptcy option.

Because the agent never goes bankrupt in this case, any unsecured loan $h$ he takes out at $t=0$ will be repaid at $t=1$ with probability one. Thus, as long as the agent's total savings are non-zero, $R>\left(1-\tau^{*}\right) r_{1}$ implies that the agent will choose $h=0$, simply because reducing savings is a cheaper form of borrowing than the unsecured loan $h$. Also, it 
is without loss of generality here to take $b=0$ because $q=1 / r_{1}$. Thus, the agent's budget constraints reduce to

$$
\begin{aligned}
c_{0}+k_{1} & \leq w_{0} l_{0}+r_{0} k_{0}-T_{0}^{*} \\
c_{1 \theta} & \leq w_{1} \theta l_{1 \theta}+\left(1-\tau^{*}\right) r_{1} k_{1}-T_{1}^{*}
\end{aligned}
$$

We need to show that the value the agent attains in this problem is less than the value delivered by the optimal allocation $A^{*}$. To show this, let us consider the following auxiliary economy. The government sets taxes $\left(\tau^{*}, T_{0}^{*}, \tilde{T}_{1}\right)$, where, as before, $\tau^{*}$ is given in (13) and $T_{0}^{*}=G_{0}$. The only asset agents trade is capital - there is no bankruptcy, unsecured loans, or bonds in this economy. Denote by $\tilde{r}_{1}$ the equilibrium interest rate obtained under this institutional structure, and by $\tilde{k}_{1}=\tilde{K}_{1}$ the amount agents save. The tax $\tilde{T}_{1}$ is set so as to cover the spending $G_{1}$, i.e., $\tilde{T}_{1}=G_{1}-\tau^{*} \tilde{r}_{1} \tilde{K}_{1}$. The equilibrium allocation from this auxiliary economy is clearly worse than the optimum $A^{*}$ because this allocation is feasible in the planning problem but does not solve it. It is now easy to verify that the solution to the problem the agent solves in Case III delivers no more utility than the equilibrium allocation from the auxiliary economy. Therefore, this utility value is smaller than the utility delivered by $A^{*}$. It was shown in Case I that the agent can attain the utility delivered by $A^{*}$ if he chooses $d_{0}=1$. Thus, what the agent can attain in Case III is less that what he can attain in Case I.

Case IV. $\left(d_{0}, d_{1}\right)=(0,1)$, i.e., the agent goes bankrupt when $\theta=1$ and does not when $\theta=0$.

In order to be eligible for bankruptcy in state $\theta=1$, the agent must choose $l_{11}=0$. He obviously also chooses $l_{10}=0$.

At the solution to this problem, the agent chooses either $h=0$ or $h>0$. Suppose first that the agent chooses $h=0$. In this case, it is better for the agent to not file for bankruptcy at all because the amount he would discharge in bankruptcy is zero, and so the agent would not benefit from subjecting his savings to the bankruptcy exemption cap $\bar{e}$. In this case, thus, the agent cannot do better than what he obtains in Case III where he maximizes his utility conditional on never filing for bankruptcy.

If $h>0$, then we can show that the strategy $\left(d_{0}, d_{1}\right)=(0,1)$ is dominated by the strategy $\left(d_{0}, d_{1}\right)=(1,1)$. (That strategy was in Case II shown to be not superior to the proposed equilibrium strategy of Case I.) Indeed, the budget constraints the agent faces conditional on $\left(d_{0}, d_{1}\right)=(0,1)$ are

$$
\begin{aligned}
h & \leq \bar{h} \\
c_{0}+q b+k_{1} & \leq w_{0} l_{0}+r_{0} k_{0}+h-T_{0}^{*}, \\
c_{10} & \leq r_{1} k_{1}+b-R h-\tau^{*}\left(r_{1} k_{1}+b\right)-T_{1}^{*}, \\
c_{11} & \leq r_{1} k_{1}+b-\max \left\{r_{1} k_{1}+b-\bar{e}, 0\right\}-\tau^{*}\left(r_{1} k_{1}+b\right)-T_{1}^{*} .
\end{aligned}
$$

We now show that at the solution to this problem with $h>0$, the agent does not save 
more than $\bar{e}$, i.e., $r_{1} k_{1}+b \leq \bar{e}$. Suppose he saves exactly $\bar{e}$, i.e., $r_{1} k_{1}+b=\bar{e}$ and consider the effects of increasing the savings by investing $\varepsilon>0$ more in capital. (The argument is the same if the agent considers increasing his bond holdings $b$.) The marginal payoff this extra investment gives at date 1 is $\left(1-\tau^{*}\right) r_{1} \varepsilon<r_{1} \varepsilon$ in state $\theta=0$ and zero in state $\theta=1$ because savings in excess of $\bar{e}$ are confiscated in bankruptcy (for which the agent files in state $\theta=1$ ). The alternative strategy of decreasing $h$ by $\varepsilon$ has the same cost at $t=0$ and pays off $R \varepsilon>r_{1} \varepsilon$ in state $\theta=0$, and zero in state $\theta=1$. Thus, the agent would prefer to reduce $h$ rather than to increase his savings above $\bar{e}$.

We now see that, keeping all other choices unchanged, the agent can increase his consumption $c_{10}$ by filing for bankruptcy in state $\theta=0$. This is simply because

$$
\begin{aligned}
r_{1} k_{1}+b-R h-\tau^{*}\left(r_{1} k_{1}+b\right)-T_{1}^{*} & <r_{1} k_{1}+b-\tau^{*}\left(r_{1} k_{1}+b\right)-T_{1}^{*} \\
& =r_{1} k_{1}+b-\max \left\{r_{1} k_{1}+b-\bar{e}, 0\right\}-\tau^{*}\left(r_{1} k_{1}+b\right)-T_{1}^{*}
\end{aligned}
$$

where the equality follows from $r_{1} k_{1}+b \leq \bar{e}$ and the strict inequality follows from $h>$ 0 . (Intuitively, given that the agent chooses savings that do not trigger confiscation in bankruptcy, there is no reason to repay the unsecured loan in state $\theta=0$ as the agent is eligible for bankruptcy in state $\theta=0$ because $l_{10}=0$ in any case.) Thus, this strategy is not better than the best strategy conditional on the plan $\left(d_{0}, d_{1}\right)=(1,1)$.

QED

\subsection{Discussion}

The mechanism that we use in this paper to implement a Mirrlees optimum is substantially different from the mechanisms studied in NDPF. In the NDPF mechanisms, agents trade a single asset, capital. In our mechanism, agents trade capital, unsecured loans, and bonds. The bankruptcy rules $(f, \bar{e})$ and the credit limit $\bar{h}$ support trade in unsecured loans in equilibrium. Because agents' bankruptcy filing decisions are state-contingent, the payoff of a portfolio consisting of a loan and bonds is tailored to each agent's individual realization of uncertainty. The asset span generated by the these assets is larger than that provided by the single asset used in NDPF implementations. The agents use this extended asset span to obtain insurance. Therefore, in our mechanism the government does not need to use fiscal policy instruments to provide insurance via ex post redistribution, which it does in NDPF. In fact, the present value of lifetime taxes that agents pay in our system does not depend on the realization of uncertainty. In the systems studied in NDPF, it does. ${ }^{10}$

Tax systems obtained in NDPF are designed to overcome the problem of joint deviations. The tax system we study here is not. Similar to Grochulski (2010), agents do not find joint deviations profitable because of the bankruptcy rules, not because of taxes. In particular,

\footnotetext{
${ }^{10}$ In Kocherlakota (2005), optimal ex post transfers are implemented via a combination of non-linear labor income taxes and state-contingent marginal capital tax rates. In Golosov and Tsyvinski (2006), these transfers are implemented via tax-funded disability transfers. In Grochulski and Kocherlakota (2010), the optimal transfers are implemented via state-contingent marginal capital tax rates and a tax-funded, statecontingent social security benefit.
} 
the joint deviation in which an agent saves more than socially optimal at $t=0$ and works less than socially optimal at $t=1$ is not profitable because the bankruptcy rules $(f, \bar{e})$ make it impossible for any agent to keep at $t=1$ both (i) the transfer that optimally goes from the productive to the unproductive agents, and (ii) the return on any savings exceeding the optimal amount. If the agent wants the transfer, he must file for bankruptcy because bankruptcy discharge is the only way in which agents can obtain this transfer. But in bankruptcy agents must give up wealth in excess of the exemption $\bar{e}$, and this exemption is set precisely at the level consistent with the optimal amount of savings.

The proportional wealth tax $\tau^{*}$ has a role in discouraging over-saving in that, in contrast to Grochulski (2010), the bankruptcy exemption caps do not bind in the utility maximization problem of an agent who does not plan to shirk. (Recall Case I in the proof of Theorem 1.) But this role is not essential. It is straightforward to follow the steps in the proof of Theorem 1 to check that the optimum can be implemented with a Ramsey capital tax with the marginal rate $\tau$ given by any number between zero and the "natural" value $\tau^{*}$ used in Theorem 1.

To see this, note that any tax rate $\tau<\tau^{*}$ is too low to close the intertemporal wedge of a non-shirker. One might suspect that agents would find it profitable to over-save if the wealth tax rate they face is $\tau<\tau^{*}$. This however is not the case because the exemption cap constraint would become binding. ${ }^{11}$ It is true that if the marginal wealth tax rate becomes sufficiently negative, agents will over-save. The threshold value $\tilde{\tau}$ at which this happens satisfies $1-\tilde{\tau}=u^{\prime}\left(c_{0}^{*}\right) / \pi_{1} r_{1}^{*} \beta u^{\prime}\left(c_{11}^{*}\right)>1$, i.e., $\tilde{\tau}<0$. Clearly, if the subsidy to savings is sufficiently large, agents will over-save because they get to keep the after-tax return on savings at least in the state $\theta=1$ in which they do not file for bankruptcy. But because the threshold number $\tilde{\tau}$ is strictly negative, this will not happen for any non-negative marginal wealth tax rate $\tau$.

If the marginal rate $\tau$ exceeds $\tau^{*}$, however, agents do find it optimal to deviate from the optimal allocation. This is because a tax rate $\tau$ higher than $\tau^{*}$ suppresses savings below $\bar{e}$ and the bankruptcy exemption cap does not bind for savings smaller than $\bar{e}$. The value $\tau^{*}$ given in (13), therefore, is the upper end of the interval containing the marginal wealth tax rates that implement the optimum in the tax/bankruptcy mechanism studied in this paper. In addition to the natural interpretation of closing the intertemporal wedge $(10), \tau^{*}$ maximizes the amount of revenue raised from wealth taxes, and, thus, minimizes the size of the lump sum tax levied at $t=1$, for a given level of government spending $G_{1}$.

\section{Conclusion}

As summarized in Kocherlakota (2010), NDPF seeks normative implications for intertemporal taxation in a Mirrlees framework. Clearly, NDPF shows what optimal taxes could be in the Mirrlees model. However, NDPF does not show what optimal taxes should be in the

\footnotetext{
${ }^{11}$ The value $\tau^{*}$ used in Theorem 1 is already too low to close the intertemporal wedge of a shirker. That is why the exemption cap constraint binds in the shirker's problem (Case II in the proof of Theorem 1).
} 
Mirrlees model. In particular, contrary to what NDPF concludes, a simple Ramsey capital tax can be optimal in the Mirrlees model.

Implementation mechanisms considered in the NDPF are restrictive in that they assume that taxes (or, more broadly, fiscal policy instruments) are the sole means for the provision of state-contingent transfers and corrective distortions in the economy. In this paper, we use a richer implementation mechanism in which other institutions, in addition to taxes, can provide insurance and distort agents' intertemporal decision margins. In the mechanism we consider, insurance and corrective distortions are provided by personal bankruptcy laws and unsecured credit limits that emerge in equilibrium. The natural Ramsey capital tax with the marginal tax rate $\tau^{*}$ distorts the intertemporal margin sufficiently to provide correct savings incentives to non-shirkers. Personal bankruptcy distortions, in turn, make the joint deviation of shirking and over-saving unprofitable.

Our analysis shows that optimal capital taxes in Mirrlees economies do not necessarily have to be complicated, as in NDPF, but can be simple, as in the traditional Ramsey analysis. To make this point, this paper uses a mechanism in which taxes interact with unsecured credit and bankruptcy laws. But this point is not specific to this particular mechanism. Other institutions may also be effective in providing insurance and corrective distortions to private intertemporal decision margins. For example, as in Chetty and Saez (2010), firms may provide insurance to workers by using compensation schemes in which labor is not always paid its marginal product. As in DaCosta and Werning (2008), an inflation tax can potentially distort agents' intertemporal decision margins.

Within our model, the optimal Ramsey tax rate is not determined uniquely. In fact, any marginal wealth tax rate $\tau \in\left[\tilde{\tau}, \tau^{*}\right]$, where $\tilde{\tau}<0$, can be a part of an optimal tax system in our mechanism. Our analysis therefore does not imply that capital taxes should be Ramsey, or at all positive. We show that the Mirrlees environment provides a role that can be fulfilled by a positive Ramsey tax on wealth. But we also show that this role can be fulfilled by other means, i.e., an optimal wealth tax can be zero.

\section{References}

Albanesi, S. and C. Sleet (2006), Dynamic Optimal Taxation with Private Information, Review of Economic Studies 73, 1-30.

Atkeson, A. and R. E. Lucas, J. (1992), On Efficient Distribution with Private Information, Review of Economic Studies 59, 427-453.

daCosta C. and I. Werning (2008), On the Optimality of the Friedman Rule with Heterogeneous Agents and Nonlinear Income Taxation, Journal of Political Economy 116(1), $82-112$.

Golosov, M., N. Kocherlakota and A. Tsyvinski (2003), Optimal Indirect and Capital Taxation, Review of Economic Studies, 569-587. 
Golosov, M. and A. Tsyvinski (2006), Designing Optimal Disability Insurance: A Case for Asset Testing, Journal of Political Economy 114(2), 257-279.

Golosov, M. and A. Tsyvinski (2007), Optimal Taxation with Endogenous Insurance Markets Quarterly Journal of Economics 122(2), 487-534.

Grochulski, B. (2010), Optimal Personal Bankruptcy Design Under Moral Hazard, Review of Economic Dynamics 13, 350-78.

Grochulski, B. and N. Kocherlakota (2010), Nonseparable Preferences and Optimal Social Security Systems, Journal of Economic Theory 145, 2055-2077.

Kocherlakota, N. (2005), Zero Expected Wealth Taxes: A Mirrlees Approach to Dynamic Optimal Taxation, Econometrica 73, 1587-1621.

Kocherlakota, N. (2010), The New Dynamic Public Finance, Princeton University Press.

Mirrlees, J. (1971), An Exploration in the Theory of Optimum Income Taxation, Review of Economic Studies 38, 175-208.

Prescott, E.C. and R.M. Townsend (1984), Pareto Optima and Competitive Equilibria with Adverse Selection and Moral Hazard, Econometrica 52(1), 21-45.

Ramsey, F. (1927), "A Contribution to the Theory of Taxation." Economic Journal 37: $47-61$.

Rogerson W. (1985), "Repeated Moral Hazard", Econometrica, 53, 69-76. 